\title{
¿Programas focalizados? ¿Por qué falta empleo en América Latina?
}

\author{
Carlos Comas* \\ * Profesor-investigador UCA y ESADE. e-mail: comas@ns.uca.edu.ni
}

Recibido: noviembre 2004 / Aceptado: diciembre 2005

EN EL MES DE NOVIEMBRE DEL 2004, SE DESARROLLÓ EN LA UNIVERSIDAD Centroamericana (UCA) el Congreso Anual de FLACSO-CLACSO-CROP con la participación de renombrados sociólogos de América Latina, quienes debatieron sobre pobreza y migraciones. El evento clausuró con una Mesa Redonda donde se presentaron ponencias sobre pobreza y migraciones. Este trabajo trata de ser una recopilación de lo dicho en esa reunió, más algunas reflexiones acerca de la focalización versus servicios universales; y por qué América Latina ha fracasado en crear empleo.

Palabras clave: mercado laboral-América latina / agencias de empleos / empleoprogramas / pobreza-América Latina / emigración e inmigración

\section{Focalización versus servicios universales}

Durante la Mesa Redonda con que finalizó el Congreso, Carlos Sojo intervino poniendo sobre el tapete el hecho de que con programas focalizados, dirigidos a las bolsas de personas extremadamente pobres, no se resuelve el problema de la pobreza. Por su parte, una participante mexicano-brasileña expuso los éxitos alcanzados por un programa focalizado de México, llamado originalmente Progresa y actualmente Oportunidades, pero reconocía que, aunque logra disminuir el número de personas extremadamente pobres, no reduce el número de las moderadamente pobres. Por ello, Sojo insistió en que, junto a esos programas focalizados, son necesarios servicios universales robustos: educación y salud que posibilitan que la gente se promocione.

En una oportunidad, Manuel Ortega, Director de CASC-UCA, afirmó que la atención a la pobreza en forma de programas focalizados, limitados a sólo las personas pobres, empezaron en los países ricos, donde son minoría. En los países subdesarrollados, son la mitad o más de la población y es imposiblemente caro atenderlos a todos. En consecuencia, se limitan a los "extremadamente" pobres a quienes hacen ascender desde la extrema pobreza a la pobreza moderada... donde los dejan. En esa ocasión, Ortega añadió que, en situación de pobreza, es difícil que la población se empodere, asuma su ciudadanía, se haga responsable de su propio futuro e intervenga activamente en la construcción del país, que es lo que se necesita. Esa es, precisamente, la insuficiencia de los programas focalizados. A partir de esta premisa, se explica la insistente demanda de Carlos Sojo en los servicios universales de educación y salud, que son los que pueden promocionar al 
conjunto moderadamente pobre.

Esta temática es impactante porque la UCA coordina un Postgrado en Gerencia de Políticas, Programas y Proyectos Sociales donde se insiste en la necesidad de gerenciar bien los "proyectos". Nicaragua está llena de "proyectos": en una comunidad, se da alimento por trabajo; en muchas escuelas, se da el vaso de leche; en tal otro lugar, se atiende a las muchachas en situación de riesgo; etc. El BID y otros organismos internacionales vuelcan enormes cantidades de recursos en financiar proyectos y, por ello, se insiste en la necesidad de gerenciarlos bien. Sin embargo, ese conjunto de proyectos, que son proyectos focalizados, no lograrán crear una base amplia de ciudadanía, de agentes del propio desarrollo.

Desde este punto de vista, se entiende el interés de la Unión Europea en dejar de financiar proyectos para pasar a vigorizar con donativos y préstamos, otorgados directamente al presupuesto del estado, los programas gubernamentales de Salud y Educación, es decir los servicios universales. Se trata del enfoque SWAP.

En los Postgrados que se coordinan en la UCA, no se olvida este aspecto, pero lo manifestado en la Mesa Redonda lleva a reflexionar y obliga a poner los proyectos en su propio lugar: gerenciar bien los proyectos, sí; pero a la vez, trabajar con más ahínco por una salud y una educación mejor para todos.

\section{Fracaso de América Latina en crear empleos}

Carlos Sojo indicó que la pobreza se produce por la falta de empleo o de un empleo suficientemente productivo y bien remunerado. El informe del BID correspondiente a $2004^{1}$ afirma que América Latina es la región del mundo con mayor tasa de desempleo abierto, y que los empleos de baja productividad (autoempleo de trabajadores no cualificados, empleadas del hogar, microempresas) constituyen ya la mitad de los empleos urbanos. También indica que la mitad de los trabajadores de América Latina ganan menos de un dólar por hora de trabajo. Si de cada empleado dependen dos personas más, significa que el trabajador y su familia cuentan con menos de dos dólares al día para sus gastos. Es decir, son pobres según los criterios del Banco Mundial. El BID finaliza realizando una llamada angustiosa a crear puestos de trabajo, a crear empresa.

A mediados de la década de los noventa, estudiosos del BID trataban de comprender las causas del diferente desempeño entre los "dragones asiáticos" (Corea, Taiwán, Hong Kong, Singapur) y América Latina: abundante empleo allá y falta de empleo acá; buen nivel de educación allá y deficiente educación acá. Entre las causas apuntadas, se señala la diferente distribución de los ingresos: igualitaria entre los asiáticos y extremadamente desigual en América Latina. Las reformas agrarias patrocinadas por los Estados Unidos en Corea y Taiwán, como barrera psicológica frente a la China de Mao, habían dado poder adquisitivo a las gentes sencillas que se habían constituido en un buen mercado para una industria naciente de productos sencillos y populares, necesitada de poco capital y creadora de empleo. En América Latina, en cambio, el mercado existente son las elites y la industria ha producido para ellas: una industria bastante tecnificada, utilizadora de capital pero de poca mano de obra. 
No se trata de profundizar en las causas de esta excepcional desigualdad de América Latina. El BID y el Banco Mundial la remiten a los tiempos coloniales y a la exportación de materias primas, época necesitada de subyugar mano de obra y expropiar tierras; ni en las consecuencias educativas de la abundancia (en Asia) y escasez (América Latina) de empleo: estímulo o desestímulo para que los padres procuren que sus hijos accedan a la educación. El tema de este trabajo es el fracaso de América Latina en la creación de empleo. En la segunda mitad del siglo XX, los gobiernos latinoamericanos mejoraron notablemente las condiciones sanitarias de sus países y, en consecuencia, la mortalidad retrocedió espectacularmente. Por ello, la población latinoamericana, entre 1950 y 2000 se ha multiplicado por más de tres y la nicaragüense por casi cinco. Esta circunstancia era un reto tremendo para el empleo: había que crear puestos de trabajo para los recién llegados y no se logró. ¿Por qué?

Una posible causa es la desigualdad existente, que no estimuló la creación de industrias de bienes populares, intensivas en mano de obra. Pero el problema va más allá: no sólo continúa sin crearse suficiente empleo, sino que además apenas mejora la productividad de las industrias ya existentes; las inversiones se dirigen a crear bancos, comercializadoras, hoteles, urbanizaciones y financiar la compra de automóviles o camionetas, pero no a la industria.

En la mesa redonda se culpó a las malas políticas gubernamentales porque allí se entendía que, para desarrollar un país, es menester la acción gubernamental y que por lo menos en Centroamérica, hay gobiernos ineficientes. Con lo que se constata, una vez más, que el Consenso de Washington ha periclitado.

\section{Historia, maestra de vida}

Los historiadores han investigado quiénes fueron los protagonistas de la primera revolución industrial del mundo, la revolución industrial de Inglaterra a mediados del siglo XVIII. En aquel momento, en Inglaterra había dos elites económicas medio emparentadas: los grandes terratenientes, a la vez aristócratas, cuyas tierras eran sus viejos feudos; y la burguesía comercial-financiera, originada en el comercio de los siglos XVI y XVII, que alumbró a las Compañías de Indias. Pero los creadores de la naciente industria no fueron ellos, sino "hombres nuevos"2.

En ese tiempo, la nueva maquinaria era aún muy rudimentaria, barata y fácil de producir: un artesano se podía construir su propio telar de madera; o un campesino modesto podía vender su pequeño pedazo de tierra y, con ese dinero, comprar algunos telares. Parece que este hecho no es nuevo en la historia: las viejas elites no captan las posibilidades de los tiempos nuevos y han de ser otros quienes tomen el relevo. Cuando la industria ya estuvo bien instalada, las viejas elites entraron en el negocio, sobre todo cuando se requirieron grandes capitales para los tendidos de ferrocarril, en el siglo XIX y, a partir de ahí, financiaron la llamada "segunda revolución industrial", la del acero, la electricidad, la química de síntesis y la del automóvil-petróleo, encabalgada entre los siglos XIX y XX.

En América Latina, las elites han surgido, sobre todo, gracias a la exportación de materias primas y su máxima aventura han sido los transportes: los ferrocarriles para exportar sus 
materias primas, en alianza con el capital extranjero; las comercializadoras y los bancos para facilitar la exportación. La mezcla parece similar a la de Inglaterra del XVIII: terratenientes y comercial-financieros; igual que allí, a esas elites les ha faltado el entusiasmo por la industria, creer en ella. El paralelismo con la Inglaterra del siglo XVIII va más allá: también en América Latina han surgido "hombres nuevos" creadores de industria... pero les ha faltado la financiación. ¿Qué hacían los grandes capitales de las elites? Emigrar a Suiza, a Wall Street o a Miami. Alberto Cimadamore señaló que, en cierto momento, los capitales argentinos fuera del país eran iguales a la abultada deuda externa de Argentina. En Europa, los capitales de las elites no emigraron, sino que acabaron entrando en el juego industrial. ¿Por qué en no ha sucedido lo mismo en América Latina?

Abelardo Morales propuso una hipótesis de trabajo: ¿Se está asistiendo a la creación de una división del trabajo geográfica a nivel mundial? En unos países se acumulan y trabajan los capitales; en otros, se reproduce la mano de obra y se instalan maquilas para que en el Norte haya jeans y computadoras baratos.

Desde hace años se sabe que la situación de los países latinoamericanos para acceder al desarrollo es muy distinta de la de los países europeos del siglo XIX. Ellos eran el primer vagón de un convoy en marcha, junto con Estados Unidos, Canadá y Japón; mientras que los países latinoamericanos son un segundo vagón. Ser segundo vagón cambia las cosas. Por una parte, da facilidades: se heredan inventos, instituciones, etc., que ya no hay que descubrir laboriosamente. Pero hay dificultades especiales: la industria latinoamericana ha de soportar la competencia de los productos más avanzados del Norte mientras sus propios productos agrícolas corren el riesgo de quedar arrumbados por los productos agrícolas subvencionados de ese mismo Norte. Más aún, el Norte deslumbra a los mejores cerebros y los arrebata, privando de su creatividad a todo un Continente.

Además, también los capitales tienden a pasar del segundo vagón al primero, donde la rentabilidad es más segura. América Latina no crea empleo porque sus capitales se fugan. Keynes habló de una "liquidity trap”, una trampa que absorbía la liquidez. En América Latina quizás se deba hablar de una "capital trap", un agujero negro, el "primer vagón", que se come los capitales de las elites y no deja que financien los nacientes esfuerzos industriales. En Europa, las elites terratenientes-comercializadoras-financieras acabaron por entrar en el mundo industrial y contribuyeron a la financiación de su desarrollo ulterior: ferrocarriles y la "segunda revolución industrial". En América Latina, los capitales de las elites no se dirigen a la naciente industria interior, sino que se fugan al mundo rico, donde obtienen más rentabilidad y seguridad. La parte de ese capital que se queda dentro financia los servicios que requiere esa misma elite: comercios, hoteles, urbanizaciones, camionetas.

El experto en América Latina Luis de Sebastián afirma que la última causa por la que América Latina no se desarrolla es la falta de patriotismo de sus elites. Desde hace tiempo se conocen las grandes fugas de capitales, pero hay un problema más estructural: la economía tiene sus leyes y, aunque el patriotismo a veces las ha podido contrarrestar, normalmente esas leyes retratan lo que hace la naturaleza humana. La experiencia histórica demuestra que los capitales de cualquier parte del mundo carecen de patriotismo y que lo que los mueve de un lado para otro es la búsqueda de la rentabilidad. Si los capitales se marchan de América 
Latina no es por un capricho de sus elites, sino porque el mundo rico, el "primer vagón”, les resulta más rentable. Y los esforzados industrializadores latinoamericanos se quedan sin esos recursos necesarios para afincar un mundo de maquinaria, fábricas y talleres.

Ante la desaparición de este fondo de capital acumulado por las elites nativas, a los gobiernos latinoamericanos se les plantea una tarea mucho más difícil que la que enfrentaron los gobiernos europeos de hace dos siglos: han de lograr una buena financiación, cosa institucionalmente nada fácil; mientras procuran compensar la precariedad, por falta de recursos, en que se encuentra el proceso industrializador, mediante un cuidado exquisito en otro tipo de políticas, entre las que no es la menor el grado de apertura al exterior.

Obviamente, todo lo contenido en este trabajo es una de esas visiones grandilocuentes que, como decía Robert K. Merton "son importantes, pero no sabemos si son verdad". La vida no es tan sencilla: las elites no son monolíticas, los países latinoamericanos son muy distintos entre sí, y harían falta monografías empíricas para saber hasta qué punto esta visión se acerca a la realidad. Sin embargo, queda en pie una sospecha: la financiación de la industrialización latinoamericana tiene dificultades serias que podrían ser estructurales. En consecuencia, se exige una atención peculiar por parte del estado. Una atención como la que el médico da a una enfermedad que se teme pueda tener raíces profundas.

\section{Notas}

1 Banco Interamericano de Desarrollo, Se buscan buenos empleos: los mercados laborales en América Latina. Informe de progreso económico y social 2004, Washington D.C.: BID, 2004

2 Bairoch, Paul, "La agricultura y la revolución industrial, 1700-1914", en Carlo M. Cipolla (ed.), Historia económica de Europa (3): la revolución industrial, Barcelona: Ariel 1979 